\title{
Discovery, Integration, Communication, Engagement: Learning Through Scaffolds in a Field-Based Course
}

Thomas Yates

University of Saskatchewan

A field-based course in an applied science program can have numerous learning outcomes. These are typically addressed through demonstration, active participation by the students, communication between students and instructor and amongststudents, and independent work by students individually or in small groups. Such courses are also opportunities for students to develop their critical thinking. The author's experience is that teaching techniques used to deliver field courses are generally inherent and based on the experience of the instructor and the teaching culture within the academic unit. These techniques are typically not drawn from the pedagogical literature, although they do have similarities to such established concepts such as scaffolds. Recognition of teaching concepts drawn from the pedagogical literature and their application to the design and teaching of field-based courses may improve the delivery of course material and provide a better student experience. Thinking and teaching in terms of the support that scaffolds represent may also smooth the transition from classroom to outdoors back to classroom. Supported learning based on established teaching methods will improve a student's opportunity for Discovery, Integration, Communication and Engagement.

\section{Introduction}

$\mathrm{F}_{\mathrm{s}}$ ield courses are a rare opportunity for undergraduate students to make their own discoveries, integrate what they observe, communicate to their peers, and engage with the community. The potential impact and value of these courses may be enhanced by applying three interrelated approaches. The first is the application of informed teaching concepts drawn from the pedagogical literature. Like many instructors I initially based my course design and teaching on practices established within the department by my peers, as well as my personal experience and knowledge. Although this intuitive approach is 
effective, student learning may be better served by consciously using concepts drawn from the literature on teaching and learning. Second, scaffolds as a teaching method is well suited for the delivery of a field-based course because they emphasize using supports such as, modeling, speak-aloud, and reciprocal teaching. Third, in keeping with the concept of scaffolds, improvements may be realized by seeing the course as part of a student learning continuum that begins where a pre-requisite course ends and finishes after submission of course products - for example, written reports for evaluation. This leads to a strategy of supporting students during these before and after periods.

\section{A Unique Undergraduate Course}

Renewable Resource Management (RRM) is an applied science degree program offered by the College of Agriculture and Bioresources that addresses a growing demand for graduates trained in sustainable land management. The program offers a suite of innovative core courses that are intended to foster inquiry-based learning - be question-driven, involve critical discourse, require self-direction, and involve students in research-type activities such as information gathering, synthesis, and communication of results. The Field Course in Renewable Resource Management (RRM 301) encapsulates the innovative learning nature of the RRM program. RRM 301 is a 20-day course, longer than typical field courses, and provides an experiential opportunity for students to not only learn field skills and critical thinking, but apply the skills and concepts through an independent group mapping project completed with minimal instructor supervision. The learning outcomes are many and varied such as the recognition of landforms, soil parent materials, soil types, plant species, and plant communities; understanding soil-landscape models and how they apply to the delineation of biophysical map units; ecosite classification; the application of sampling strategies, interpretation of soil, forestry, and topographic maps; and the collection of georeferenced and forest mensurative data. A single learning outcome may require a student to learn and apply numerous skills, in addition to the use of the cognitive strategies for interpretation and aggregation of field data.

The original design and delivery of the course is illustrated in Figure 1. The course was envisioned to begin on the first field day and end on the last, even though the submission of a field map and report was at a later date. The course was delivered through a variety of site visits and field exercises that proceeded in a linear progression. Exercises were supported by a course manual that provided a summary of each activity. Skills were demonstrated, practiced, and related to relevant scientific concepts. The complexity of the activities increased over time and successful completion of each exercise required skills and knowledge acquired at previous site visits. It was intended that through these exercises the students would acquire the field skills and knowledge necessary to operate with minimal supervision in regard to safety, data collection and decision-making during independent group mapping project. During this latter two-week period student groups of 3-4 were assigned a land area of approximately 50 hectares. Instructors saw the student groups 1 to 2 times during the day and these visits were short with a focus on providing support to enable student decision-making.

This course was designed and developed based on my experience as researcher and instructor in addition to past practices within the department in regard to existing field-based courses. With enrollment capped at 24 , the relationship between instructor and student had a significant component of one-on-one interaction. Day to day teaching took the general form of demonstration on the part of the instructor and practice on the part of the student with opportunities for peer-peer instruction. Skills acquired were subsequently utilized in combination to perform a larger task. Formal teaching concepts from scholarly literature on teaching and learning were not investigated during the development period or applied during the initial delivery of the course. In hindsight, the student was directed to focus on the doing rather than understanding. It is my opinion that the lack of investigation and application of formal teaching methods is not an uncommon approach in the teaching of science courses and certainly fits 
with the more general problem of bridging the gap between pedagogical research and the use of that research in teaching.

\section{Challenges}

Evaluation of RRM 301 in terms of course content and student experience, based on Student Evaluation of Education Quality (SEEQ) and peer evaluation of classroom performance, has been very positive over the first two offerings of the course. However, from my experience, the experiential nature of field-based courses usually makes them very popular. Thus, high importance was placed on rare negative comments provided by students. Such comments included feelings of a lack of preparation for the field course, and of a loss of support between the end of the field work and the submission of the final report. I also felt that there is mixed success in achievement of learning outcomes related to basic field skills. Some skills were disproportionately applied by students during the independent group mapping project. Thus, as students began the last two weeks of the course I did not consider them to be equally positioned to discover, integrate, communicate, and engage.

\section{A Teaching Concept}

A review of the pedagogical literature indicated that the course structure of RRM 301 had similarities to the teaching of higher-level cognitive strategies using scaffolds (Wood, Bruner, \& Ross, 1976). Rosenshine and Meister (1992) describe scaffolds as methods used to support a student's learning between what they are currently able to do and the ability they are attempting to acquire. These methods include the use of demonstration (modeling), verbal prompts (think-aloud), concrete supports, and reciprocal teaching. Application of these methods involves the introduction of course material in small steps, at first simple, but then increasing in complexity. Scaffolds are considered to be temporary and the instructor removes the support as students master the skill leading to independent practice.

Similar to using scaffolds, field skills taught in RRM 301 were first modeled and explained much like using a verbal prompt to support learning. Prompts, as described by Englert, Raphael, Anderson, Anthony, and Stevens (1991) were part of the course manual. Also, students working in small groups were asked to demonstrate findings to other students and the instructor $-\mathrm{a}$ form of reciprocal teaching (Brown \& Campion, 1986; Palincsar \& Brown, 1984). In RRM 301, course material is initially simple and introduced in small steps, but gradually becomes more complex. During the last 10 days of RRM 301 support diminishes leaving the students to work in groups to complete the mapping exercise with little reliance on instructors.

The original design of RRM 301 did not formally incorporate scaffolds as a teaching method. However, it is possible that their formal application may improve the successful achievement of learning outcomes. For example, a conscious use of 'thinkaloud' may focus the instructor on being more explicit in revealing her or his thought process as they demonstrate as skill, such as the description and classification of soil development. Small steps in this cognitive process, possibly not revealed by the instructor due to their familiarity with the technique

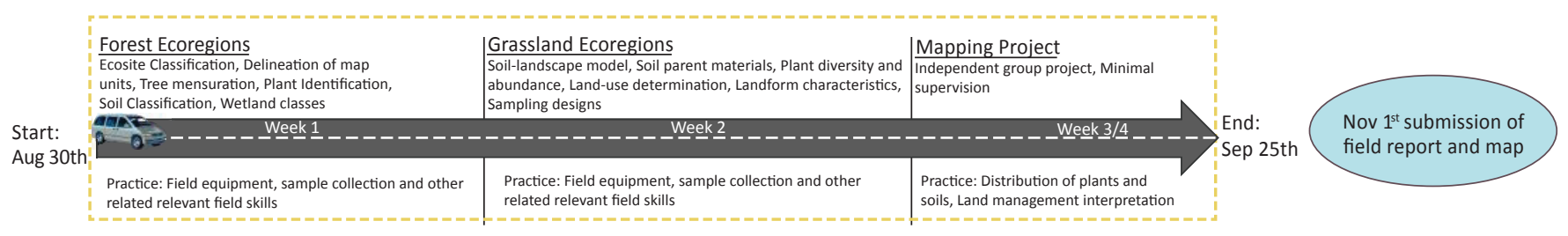

FIGURE 1

Original Approach to Achieving Learning Outcomes in RRM 301 
and unintentionally rendered implicit, may indeed make the difference in the understanding of the application of the technique for certain students. Instructors conscious of the teaching concept being applied may skip fewer or none of these implicit steps leading to better student understanding of the technique and a better experience overall during the latter part of the course when students are working independently.

Equally important is a formal use of student think-aloud (Nielsen, Clemmensen, \& Yssing, 2002). Think-aloud used by both instructor and student can foster a dialogue that allows assessment of the student's understanding and effective reciprocal teaching. Dialogue and modeling are commonly used to teach reading comprehension skills (Doolittle, Hicks, Triplett, Nichols, \& Young, 2006; Palincsar \& Brown, 1984; Rosenshine \& Meister, 1994; Zoller, 2002). During RRM 301 a student may explain how they describe and classify a soil, and reveal to the instructor what they know and how they are applying that knowledge. As well, concrete supports in the form of think-sheets have been shown to support students as they develop the ability to question text as part of comprehension (Rosenshine \& Miester, 1992). In RRM 301, the course manual could incorporate think-sheets by including prompts in the form of questions that provide the student support during the exercise and also serve as a means of reflection to reinforce the learning outcomes.

\section{Rethink}

Formal implementation of scaffolds would involve a rethink of the course content and delivery; however, it is unlikely, due to the similarities between the formal teaching concepts and the current teaching of the course, that a complete redesign of the course would be necessary. A conscious application of scaffolds may lead to the course being envisioned as in Figure 2. Rather than thinking of the course as a series of scheduled stops (Figure 1), the thinking will be on building skills and learning concepts. The sites used will serve as a context to the delivery of the skill rather the exercise serving as reason to visit the site. The instruction during the first two weeks will be delivered incrementally, building the students toward the ability to execute the independent group mapping project in the latter half of the course. The end of the course would now be the submission of the field report and map (post-field completion), and that period between the final field day and report submission could be supported with additional instructor time in the form of tutorial sessions focused on map creation techniques and data interpretation.

One could view the concept of scaffolds and the associated teaching techniques as applied at two scales. The first is the use modeling, think-aloud, reciprocal teaching and concrete supports for day to day activities that focus of the transfer of relevant field skills and concepts. The second is bridging the gap between the pre-requisite course and the field map and report. This achieved by increasing the complexity of exercises and removing support on previously acquired skills, but requiring their application in more complex activities.

A new course design using the concept of scaffolds may address the previously cited concerns. Greater achievement of learning outcomes and student's realizing more support may lead to higher test scores, and more informative field maps and

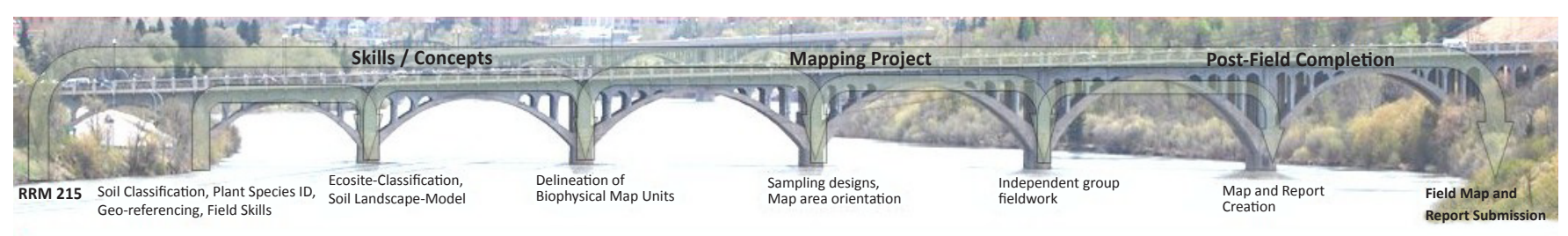

FIGURE 2

New Approach to Achieving Learning Outcomes Based on Scaffolds 
reports. However, the formal use of these techniques and the concept of support may introduce challenges at the aforementioned scales. The day-to-day use of reciprocal teaching and think-aloud is an intensive, potentially exhausting approach to teaching in the field. Daily objectives may need to be modified to allot time for students to verbalize their thoughts in detail. A field-based course with extended contact hours to accommodate tutorial sessions may negatively impact student engagement and have resource implications. Contact hours related to report and map development may be more effectively offered and enhanced as a subsequent course for credit. The development of a subsequent course for the purpose of teaching the applied techniques in geographic information systems needed for map creation could be case-based drawing on RRM 301. This would complete a learning continuum that bridges a gap from the perquisite lecture based course to applied case-based instruction with the experiential fieldbased course as a key support between.

\section{References}

Brown, A.L. \& Campion, J.C. (1986). Psychological theory and the study of learning disabilities. American Psychologist, 14, 1059-1068.

Doolittle, P.E., Hicks, D., Triplett, C.F., Nichols, W.E., \& Young, C.A. (2006). Reciprocal teaching for reading comprehension in higher education: A strategy for fostering the deeper understanding of texts. International Journal of Teaching and Learning in Higher Education, 17, 106-118.

Englert, C.S., Raphael, T.E., Anderson, L.M., Anthony, H.M., \& Stevens, D.D. (1991). Making strategies and self talk visible: writing instruction in regular and special education classrooms. American Education Research Journal, 28, 337-372.

Nielsen, J., Clemmensen, T., \& Yssing, C. (2002). Getting access to what goes on in people's head? Reflections on the think-aloud technique. Proceedings from the Second Nordic Conference on Human-Computer Interactions, 19-23.

Palincsar, A.S. \& Brown, A.L. (1984). Reciprocal teaching of comprehension-fostering and comprehension-monitoring activities. Cognition and Instruction, 1(2) 117-175.

Rosenshine, B. \& Meister, C. (1992). The use of scaffolds for teaching higher-level cognitive strategies. Educational Leadership, 49, 26-33.

Rosenshine, B., \& Meister, C. (1994). Reciprocal teaching: A review of the literature. Review of Educational Research, 64, 479-530.

Wood, D., Bruner, J.S., \& Ross, G. (1976). The role of tutoring in problem solving. Journal of Child Psychology and Psychiatry, 17, 89-100.

Zollar, U. (2002). Algorithmic, LOCS and HOCS (chemistry) exam questions: Performance and attitudes of college students. International Journal of Science Education, 24, 185-203.

\section{Biography}

Thomas Yates is a Lecturer at the University of Saskatchewan, Department of Soil Science. He designs and delivers science courses that focus on applied skills, experiential learning. 